\title{
The effect of radiation shields around the air condenser and compressor of a refrigerator on the temperature distribution inside it
}

\author{
Clito Afonso*, Joaquim Matos \\ Faculdade de Engenharia da Universidade do Porto, R. Dr. Roberto Frias, 4200465 Porto, Portugal
}

Received 12 January 2005; received in revised form 16 January 2006; accepted 30 January 2006

\begin{abstract}
In almost all domestic refrigerators-freezers all components are assembled in the same relative position since several years ago. It is also known that the condenser releases heat at high temperatures (first law of thermodynamics) as well as the compressor. This heat is rejected to the environment in almost all practical situations partially by natural air convection. However, part of it is due to thermal radiation that causes an overheating of the refrigerator-freezer surfaces adjacent to those equipments. As a consequence there are more heat gains to the refrigerator-freezer through these surfaces and hence higher air temperatures inside. This paper describes how a simple technique can be very useful in order to minimize that part of heat transfer by radiation. The improvement is achieved by placing a radiation shield - a sheet of aluminium foil - over the surfaces close to the condenser and the compressor. For validating this technique a refrigerator-freezer was monitored with thermocouples for the measurements of the inside air temperatures in two situations: with and without the radiation shield. Results show that with this practice the average inside air temperatures in the refrigerator-freezer could decrease to about $2 \mathrm{~K}$. An available commercial code was used in order to simulate the air temperature distribution and air velocities inside the refrigerator cabinet in both situations. Results from the experimental apparatus and from simulations show that there is a good agreement between them which validates the experiments carried out.
\end{abstract}

Also an available commercial code, the Fluent, was used to simulate the internal air temperature in both situations. (C) 2006 Elsevier Ltd and IIR.

Keywords: Freezers; Refrigerators; Air temperature and air velocities inside freezers; Radiation shields

\section{Introduction}

Since long time ago all the components of commercial domestic refrigerators-freezers have been assembled in the same relative position. The four typical equipments of the vapor compression refrigeration systems, the evaporator, compressor, expansion valve and the condenser, are placed

\footnotetext{
* Corresponding author. Tel.: +351 225081746.

E-mail address: clito@fe.up.pt (C. Afonso).
}

almost in the same position in all the refrigerators-freezers. While the compressor is located in a recess at the bottom of the refrigerator, the natural air-cooled condenser is located in the rear wall of the refrigerator. Of course there have been differences in the refrigerators along the time mainly due to minor esthetic aspects and, of course, due to the use of the new zero depletion ozone refrigerants [1,2]. Thermodynamically speaking, all refrigerators are based on conventional vapor compression refrigeration cycles $[3,4]$. Usually the refrigerant after adiabatic expansion in a capillary tube or some type of expansion valve [5] flows 


\begin{tabular}{|ll|}
\hline Nomenclature \\
$\vec{F}$ & external body forces \\
$\rho \vec{g}$ & gravitational body force \\
$p$ & static pressure \\
$\mathrm{Sm}$ & mass added \\
$\vec{v}$ & velocity \\
Greek & letters \\
$\tau$ & time \\
$\rho$ & density \\
$\vec{\Gamma}$ & stress tensor \\
\hline
\end{tabular}

through the freezer evaporator and then through the refrigerator evaporator. After heat gain in both spaces, the refrigerant effect, the refrigerant is compressed and then releases the accumulated energy in the condenser, usually of a natural air-cooled type, closing in that way the refrigeration cycle.

Previous experimental work done [6,7] had shown that the outside surface temperature of the rear wall where the condenser is located as well as the walls close to the compressor have a much higher temperature than the outside air with which all freezer-refrigerator surfaces exchange heat. This is due to the heat release from the condenser and from the compressor. This causes larger heat gains to the freezer-refrigerator through those walls when compared with the others.

In order to evaluate the effect of the heat release of the condenser and the compressor on the thermal behavior of this kind of equipment, tests have been done in a new commercially available refrigerator-freezer. Modifications in the rear wall and in the recess walls where the compressor is located in the refrigerator-freezer have been carried out separately in order to evaluate the individual influence of each modification. In this work, the modifications simply consist in placing a radiation shield composed of a sheet of aluminium foil glued over to these walls. After the evaluation of the influence of each modification of the surfaces on the internal air temperatures and energy consumption of the compressor a final test was done with the radiation shield placed simultaneously in the rear wall and in the recess walls of the compressor.

The refrigerator-freezer was monitored with previously calibrated thermocouples and with an energy meter. All the measured values were recorded in a data logger, [8], for further analysis.

With the measured temperatures of the interior walls of the refrigerator cabinet as boundary conditions for a commercial available code, Fluent [9], simulation of all air temperature distributions and air velocities were obtained. The simulated temperatures were compared with the measured ones, the overall differences being very small, which validate the simulation carried out.
Results have shown that application of radiation shields (aluminium foil or some reflective painting) to improve thermal insulation properties, $[10,11]$, when used in refrigerators-freezers, is an effective way to decrease the internal air temperatures and only with minor additional costs. In the tests carried out differences around $2 \mathrm{~K}$ were recorded.

\section{Methodology}

The freezer, Fig. 1, works with a standard vapor compression cycle with $0.13 \mathrm{~kg}$ of R-134a as a refrigerant. The refrigerant after adiabatic expansion in the capillary tube enters the upper cabinet freezer (negative air temperatures) and then flows to the refrigerator evaporator (positive air temperatures). The cycle is closed with the refrigerant flowing through the hermetic compressor sited at the bottom of the refrigerator and after through the natural convection air-cooled condenser. The compressor has a nominal current of $0.77 \mathrm{~A}$ and a nominal voltage of $220 \mathrm{~V}$. The net inside volume is 2241 .

The double door refrigerator-freezer was monitored with previously calibrated thermocouples type $\mathrm{T}$ (copper, constantin) and located in several points of the internal

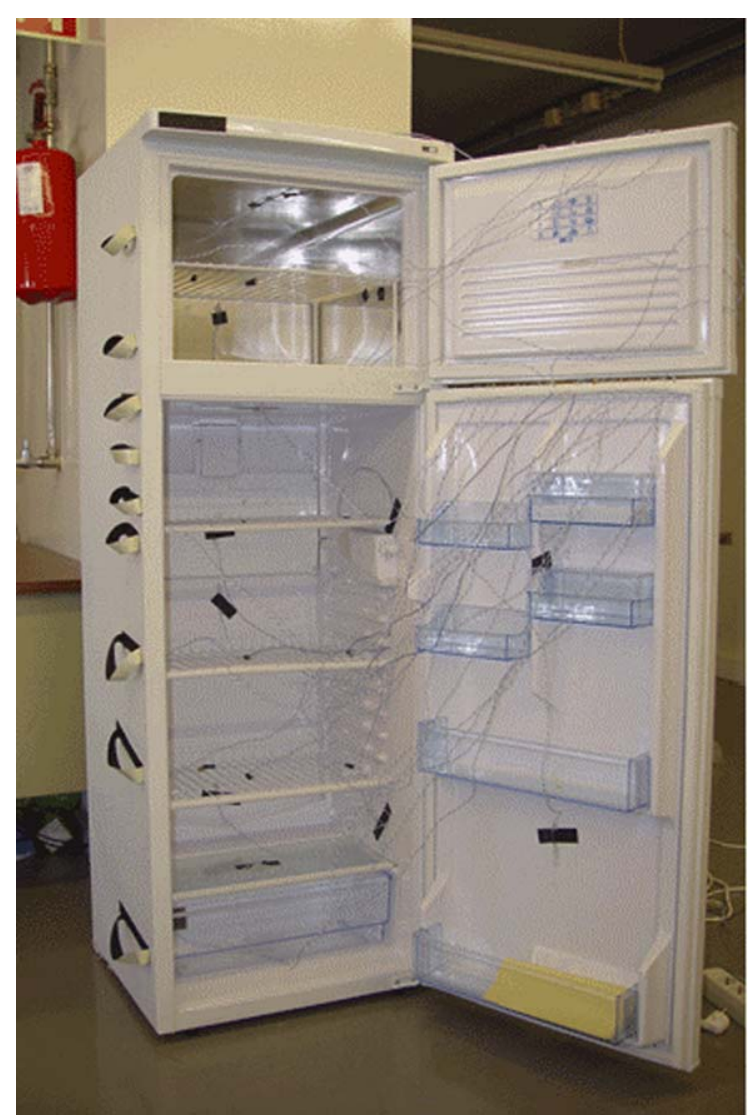

Fig. 1. View of the refrigerator-freezer. 

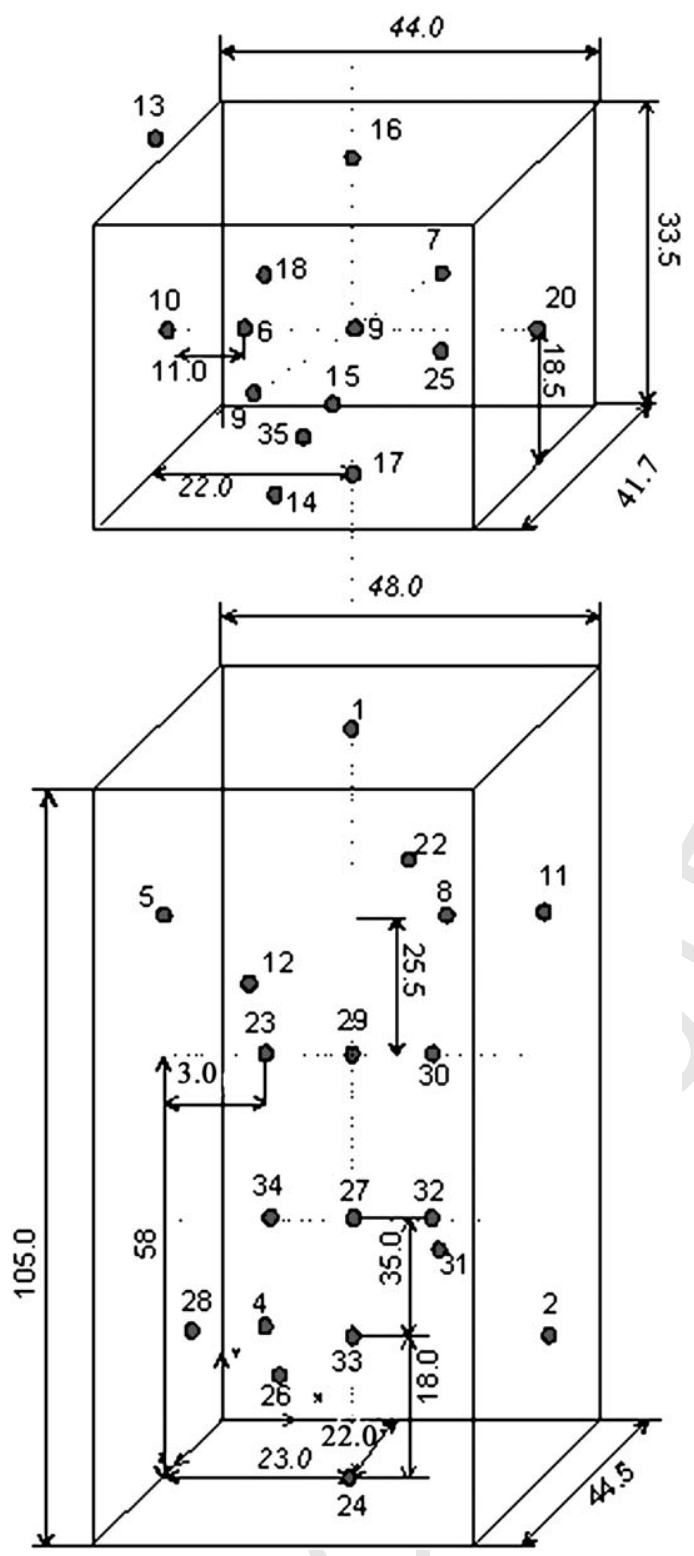

Fig. 2. Location of the thermocouples inside the refrigeratorfreezer.

surfaces, outside surfaces, inside air in both cabinets (at three different levels) and outside air, numbered as shown in Fig. 2. This location of the thermocouples enables to measure all the spatial inside surface temperatures as well as the inside air temperatures. For the test with the aluminium foil, three additional thermocouples no. 15, 18 and 25 (not shown in Fig. 2) where placed on the inside surface of it. All thermocouples, which have an uncertainty of $\pm 0.25{ }^{\circ} \mathrm{C}$, were connected to a data acquisition system that reads all temperatures at $20 \mathrm{~s}$ intervals. As it was necessary to have the right spatial positions of all inside air thermocouples, they were fixed on rulers to be possible to compare the measured values with the simulated ones from the Fluent.

At the same time the compressor power and energy consumption were measured and the results were kept in a conventional PC for later analysis.

The radiation shield used in the tests was of the type of aluminium foil with a thickness of $3 \mu \pm 5 \%$. The emissivity (value given by the producer) is 0.07 .

Four tests were carried out: the first one with the refrigerator-freezer as it comes from the factory (reference test), the second one with the radiation shield on the rear wall, a third one with the radiation shield in the recess of the compressor and finally a fourth one with the radiation shield on the rear wall and on the recess.

In all the tests the refrigerator-freezer had no internal loads and at the beginning it was in thermal equilibrium with the ambient air (door open). All tests ended when steady state was reached, i.e., when the refrigeration cycles were similar. During the entire tests, the door of the freezer and of the refrigerator was permanently closed.

The measured temperatures of the internal walls were used as input in a commercial code, [9], as boundary conditions, to simulate all spatial and temporal surface temperatures, inside air temperatures as well as air velocities in one point or plane inside the freezer.

\section{Results}

\subsection{Original refrigerator-freezer}

The temperature evolution measured with the thermocouples mentioned in Section 2 and located on the points shown in Fig. 2 is shown in Figs. 3 and 4 for the refrigerator and the freezer, respectively.

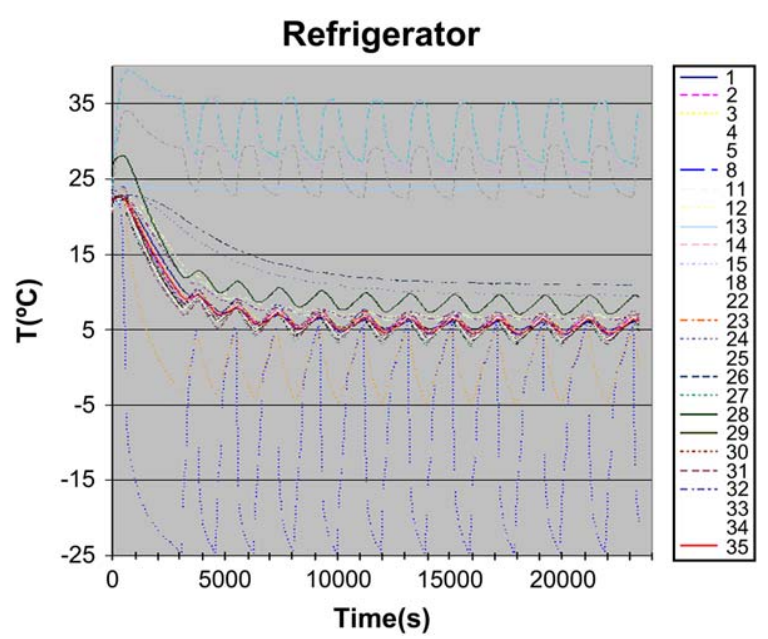

Fig. 3. Temperature evolutions in the refrigerator. 


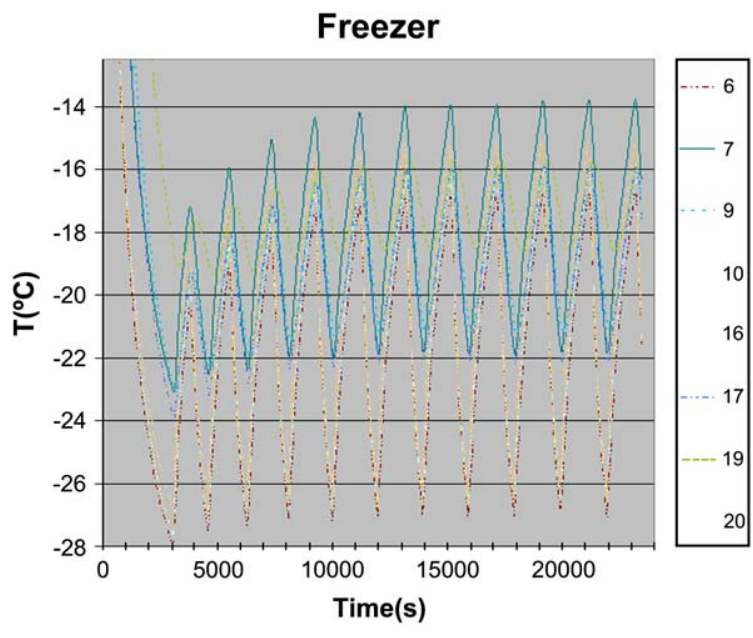

Fig. 4. Freezer surface wall and air temperatures.

The transient regime took approximately $51 \mathrm{~min}$ from the starting point in which the freezer was in thermal equilibrium with the outside environment until the minimum surface temperature of the evaporator was reached and the compressor stopped working. From Fig. 3 it can also be seen that the compressor works between a maximum surface evaporator temperature of $5.5^{\circ} \mathrm{C}$ and a minimum of $-24.5{ }^{\circ} \mathrm{C}$, and stopped working in the reverse direction of the so mentioned temperatures (thermocouple 4 - bottom curve of the graph). The entire cycle takes about $35 \mathrm{~min}$, being approximately $42 \%$ of the time spent with the compressor working and the other $58 \%$ when the compressor stopped working (Table 1).

The measured outside air temperature in the laboratory was almost constant and equal to $23.8^{\circ} \mathrm{C}$ with a standard deviation of $0.2{ }^{\circ} \mathrm{C}$ (thermocouple 13) - horizontal fourth line from the top of Fig. 3.

Generally speaking, all the measured temperatures of the inside air follow the compressor working cycle (set of 10 lines almost superimposed in the middle of the figure, third line from the bottom of the figure). On the top of these lines are the ones that represent the measured wall temperatures. The first three are also superimposed and with a much lower

Table 1

Compressor cycle operation for different locations of the radiation shield

\begin{tabular}{lllll}
\hline Radiation shield & $\begin{array}{l}\text { Cycle time } \\
(\mathrm{min})\end{array}$ & $\begin{array}{l}(\%) \\
\text { Stopped }\end{array}$ & $\begin{array}{l}(\%) \\
\text { Running }\end{array}$ & $\begin{array}{l}\text { Time to reach } \\
\text { steady state } \\
(\mathrm{min})\end{array}$ \\
\hline Without & 33.3 & 61.0 & 39.0 & 51 \\
Rear wall & 35.3 & 61.3 & 38.6 & 42 \\
Comp. recess & 34.3 & 62.1 & 37.8 & 42 \\
$\begin{array}{l}\text { Rear wall + comp. } 36.3 \\
\text { recess }\end{array}$ & 62.4 & 37.6 & 52 \\
\hline
\end{tabular}

temperature amplitude when compared with the air temperatures. Over these ones is the line that represents the bottom left wall temperature (thermocouple 28). On an average the temperature is about $4 \mathrm{~K}$ higher than the other ones and with much larger amplitude of temperature. This is due to the heat release of the compressor sited close to this surface.

Over these lines there are two more that describes also the wall temperatures and shows an exponential decay until steady state is reached and then a constant temperature is attained (fifth and sixth line from the top of the figure). These temperatures were measured inside the existing bottom box for vegetables in the left wall (thermocouple 24) and on the bottom (thermocouple 26). While the first one is due to the existing bottom box for vegetables that somehow isolates this part of the refrigerator from the upper part, the second one is due to the proximity of the compressor and also due to the mentioned box. The measured temperature of this surface when steady state is reached is about $2{ }^{\circ} \mathrm{C}$ higher than the left one.

The temperature of the wall that supports the evaporator was also measured (thermocouple $22-$ second line from the bottom of the graph). As can be seen it is the wall that has the lowest temperature. The maximum temperature picks are similar to the evaporator surface while the minimum measured temperature is around $-4{ }^{\circ} \mathrm{C}$.

The outside surface temperature of the rear wall was also measured by three thermocouples $(15,18$ and 25 as already mentioned) - first three lines from the top of the figure. While the first two are in front of the air condenser and are affected in a very similar way by the heat release from it, the last one is located above the others not being so affected by the air condenser. So, while in the first two the measured temperatures varied on average from $27.0{ }^{\circ} \mathrm{C}$ to $35.3{ }^{\circ} \mathrm{C}$, in the last one the variation lies between $23.0{ }^{\circ} \mathrm{C}$ and $29.0{ }^{\circ} \mathrm{C}$.

The inside air temperatures of the refrigerator are in some points higher than the recommended one for this kind of refrigerator, which should be between 5 and $7{ }^{\circ} \mathrm{C}$, [12-14]. Table 2 shows the maximum and minimum air temperatures measured by the three thermocouples located on four different levels (see Fig. 2). These temperatures were recorded in the vicinity time of the start and stop of

Table 2

Minimum and maximum inside air temperature at different heights in the refrigerator $\left({ }^{\circ} \mathrm{C}\right)$ for different locations of the radiation shield (rs)

\begin{tabular}{lllll}
\hline $\begin{array}{l}\text { Height } \\
(\mathrm{cm})\end{array}$ & Without rs & $\begin{array}{l}\text { Rear wall } \\
\text { with rs }\end{array}$ & $\begin{array}{l}\text { Recess } \\
\text { with rs }\end{array}$ & $\begin{array}{l}\text { Real wall } \\
\text { + recess with rs }\end{array}$ \\
\hline 83.5 & $4.5 / 6.6$ & $4.3 / 6.9$ & $4.1 / 5.9$ & $3.9 / 6.3$ \\
58 & $3.8 / 7.0$ & $2.6 / 6.9$ & $3.7 / 6.3$ & $2.5 / 5.2$ \\
53 & $2.9 / 7.4$ & $1.8 / 6.3$ & $2.5 / 6.1$ & $1.1 / 5.1$ \\
35 & $3.1 / 6.5$ & $2.3 / 5.7$ & $2.2 / 5.3$ & $1.8 / 5.6$ \\
$T_{\text {aver. }}$ & $3.6 / 6.9$ & $2.8 / 6.5$ & $3.1 / 5.9$ & $2.3 / 5.5$ \\
$\sigma$ & $0.6 / 0.35$ & $0.93 / 0.49$ & $0.79 / 0.37$ & $1.0 / 0.47$ \\
\hline
\end{tabular}


the compressor during steady state. As can be seen, in the medium and bottom levels of the refrigerator, the maximum air temperature exceeds the recommended ones. It is also possible to conclude that the inside air temperatures decrease on average from top to bottom when the compressor is running (minimum air temperatures). This is due to the effect of the evaporator. In an opposite way, when the compressor is stopped the inside air temperatures increase from top to bottom of the refrigerator (maximum air temperatures). This is due to the effect of the dividing top wall of the refrigerator-freezer that is much colder than the other surfaces. However, the average air temperatures in the medium height of the refrigerator are higher when compared with the other ones and the recommended ones. This is due to a stagnant air zone in that region already verified with thermal simulations carried out [8].

The results obtained in the freezer are shown in Fig. 4. As it can be seen, the surface temperatures of the top, bottom, left and right walls are coincident (thermocouples 6, 10, 16 and 20 - superimposed bottom lines and strongly oscillating). This is due to the evaporator that is located on those surfaces. After steady state, their measured minimum temperature is about $-27{ }^{\circ} \mathrm{C}$ and maximum is about $-15^{\circ} \mathrm{C}$. The rear wall is the one that shows higher temperatures when compared to the others (thermocouple 7 - top line of the figure). This is due to the presence of the hot air condenser close to this surface that gives rise to higher heat gains through this surface and hence higher inside wall temperature. The maximum measured inside wall temperature after steady state is $-13.8^{\circ} \mathrm{C}$ and the is minimum $-17.5{ }^{\circ} \mathrm{C}$. The inside surface door temperature (thermocouple 19) lies between the others. The two measured inside air temperatures have the same values (thermocouples 9 and 17) and so their representative lines are superimposed in the figure (second line from the bottom of the figure). After steady state the maximum and minimum air temperatures are $-16{ }^{\circ} \mathrm{C}$ and $-22.2{ }^{\circ} \mathrm{C}$, respectively. The air temperatures inside the freezer (thermocouples 6 and 9) varied between $-16{ }^{\circ} \mathrm{C}$ and $-21^{\circ} \mathrm{C}$, Table 3 , which match the regulations.

\subsection{Radiation shield only on the rear wall, only on the compressor recess and on both surfaces of the refrigerator-freezer}

Energy efficiency is improved by the application of a radiation shield. Several possibilities were investigated in the

Table 3

Minimum and maximum inside air temperature in the freezer $\left({ }^{\circ} \mathrm{C}\right)$ for different locations of the radiation shield

\begin{tabular}{ll}
\hline Radiation shield & Air temperatures \\
\hline Without & $-22.2 /-16$ \\
Rear wall & $-21.4 /-16$ \\
Comp. recess & $-20 /-17$ \\
Rear wall + comp. recess & $-22 /-16$ \\
\hline
\end{tabular}

same way as for the refrigerator-freezer system without radiation shield. Tests were carried out independently, one by one. The aluminium foil was glued first on the rear wall of the refrigerator-freezer (the three thermocouples 15, 18 and 25 where then covered by it), then on the compressor recess and finally on both the surfaces. The going of the temperature evolutions in the three tests are identical to Figs. 3 and 4, respectively for the refrigerator and freezer, except for the temperature limits and cycle times. The main results are shown in Tables $1-3$.

As it can be seen in these three cases the cycle time is longer when compared with the refrigerator-freezer in its original situation due to the increased time when the compressor does not work. It can also be seen that the compressor running time is lower. Regarding the time to reach the steady state no conclusion can be drawn from the tests as there is a significant reduction in time when the radiation shield is located only in the rear wall and only in the compressor recess ( 9 min less than the original situation) and there is an increase in time when the radiation shield is located over both the surfaces ( 1 min more than the original situation).

Regarding the air temperatures inside the refrigerator it can be seen that the minimum air temperatures decrease from the top to the bottom of the refrigerator, except for the lower level (located at a height of $35 \mathrm{~cm}$ ) that is on average slightly higher than the immediate upper level (height of $53 \mathrm{~cm}$ ). As these air temperatures are reached when the compressor did not work, this can be explained by the cooling effect of the much colder evaporator. It can also be seen that the minimum inside air temperatures are reached when the radiation shield is mounted on the rear wall and on the compressor recess. Thus, it can be concluded that the radiation shield has a positive effect on the air temperatures inside the freezer system.

Regarding the maximum inside air temperatures inside the refrigerator (when the compressor is about to start running) it can be seen that on average they increase from bottom to the top of the refrigerator. This is expected due to the heat gain through the walls.

Again, the radiation shields located in the rear wall of the refrigerator and in the compressor recess have an effect of lowering on average the inside air temperatures.

Concerning the freezer, there are no significant variations in the air temperatures due to the location of the radiation shields, Table 3 .

\subsection{Thermal simulations of the refrigerator-freezer}

For the 3D thermal simulations the standard $k-\varepsilon$ turbulent flow model was used in a commercial available code, the Fluent. This program based on a finite volume method, [15], solves the conservation equations for mass and momentum, respectively, Eqs. (1) and (2):

$\frac{\partial \rho}{\partial \tau}+\nabla(\rho \vec{v})=\operatorname{Sm}$ 
$\frac{\partial}{\partial \tau}(\rho \vec{v})+\nabla(\rho \vec{v} \vec{v})=\nabla p+\nabla \vec{\Gamma}+\rho \vec{g}+\vec{F}$

These equations were integrated over each small control volume around discrete points in the flow domain. The grid resolution has 432000 control volumes. A non-uniform grid was used to reduce the volumes and was refined close to the walls. The minimal and maximal control volumes were, respectively, $1.101 \times 10^{-8} \mathrm{~m}^{3}$ and $7.155 \times 10^{-6} \mathrm{~m}^{3}$. The convergence criteria were $10^{-2}$ for the mass conservation equation and superior to $10^{-5}$ for other equations.

For the mathematical model, the refrigerator cabinet was considered as a parallelepiped with internal dimensions of $(1.05 \times 0.48 \times 0.45) \mathrm{m}^{3}$ and the air inside was the default fluid. The measured temperatures of all internal surfaces (two in each vertical surface and one in each horizontal surface) were used as boundary conditions in the code. It can be found in the literature of similar simulations, but the boundary conditions were constant and calculated, not measured [16]. The maximum air temperature difference between the measured and simulated ones was about $1 \mathrm{~K}$, which is a quite good result $[17,18]$.

Figs. 5 and 6 show the results obtained with this code for the simulated refrigerator as it come from the factory and with the radiation shield on the rear wall and compressor recess, respectively. The results of the thermal simulations were obtained for the minimum evaporator temperature. As can be seen in the central plane (plane perpendicular to the door and on the center of the refrigerator) as well as in the lateral plane (plane parallel to the door and in the center of the refrigerator) - first two sketches of Figs. 5 and $6-$ there are lower air temperatures inside the refrigerator when the radiation shield is placed. As can also be seen in the velocities' profiles (shown as vectors) on three different levels - bottom sketch of Figs. 5 and 6 - there are two main air loops inside the refrigerator: one clockwise with a leg of descending cold air close to the evaporator and an ascending warmer air leg close to the door (see central plane); a second one, not so clear, but somehow also clockwise. It is also possible to conclude that in the central part of the refrigerator there is an almost stagnant air zone (very low air movements) as already noticed in the measurements (see Table 2). This effect is most pronounced for the system without radiation shield. These conclusions can also be seen in the graphs of temperature and velocities' distributions in three different horizontal levels inside the refrigerator.

\subsection{Energy consumption}

In spite of a slight decrease in the percentage of the running time of the compressor with the location of the radiation shield in all the rear sides of the refrigerator-freezer, the energy consumption of the compressor is almost constant, about $0.031 \mathrm{kWh}$ per cycle in all tests. This may be due to the control thermostat that is located in the mid-height
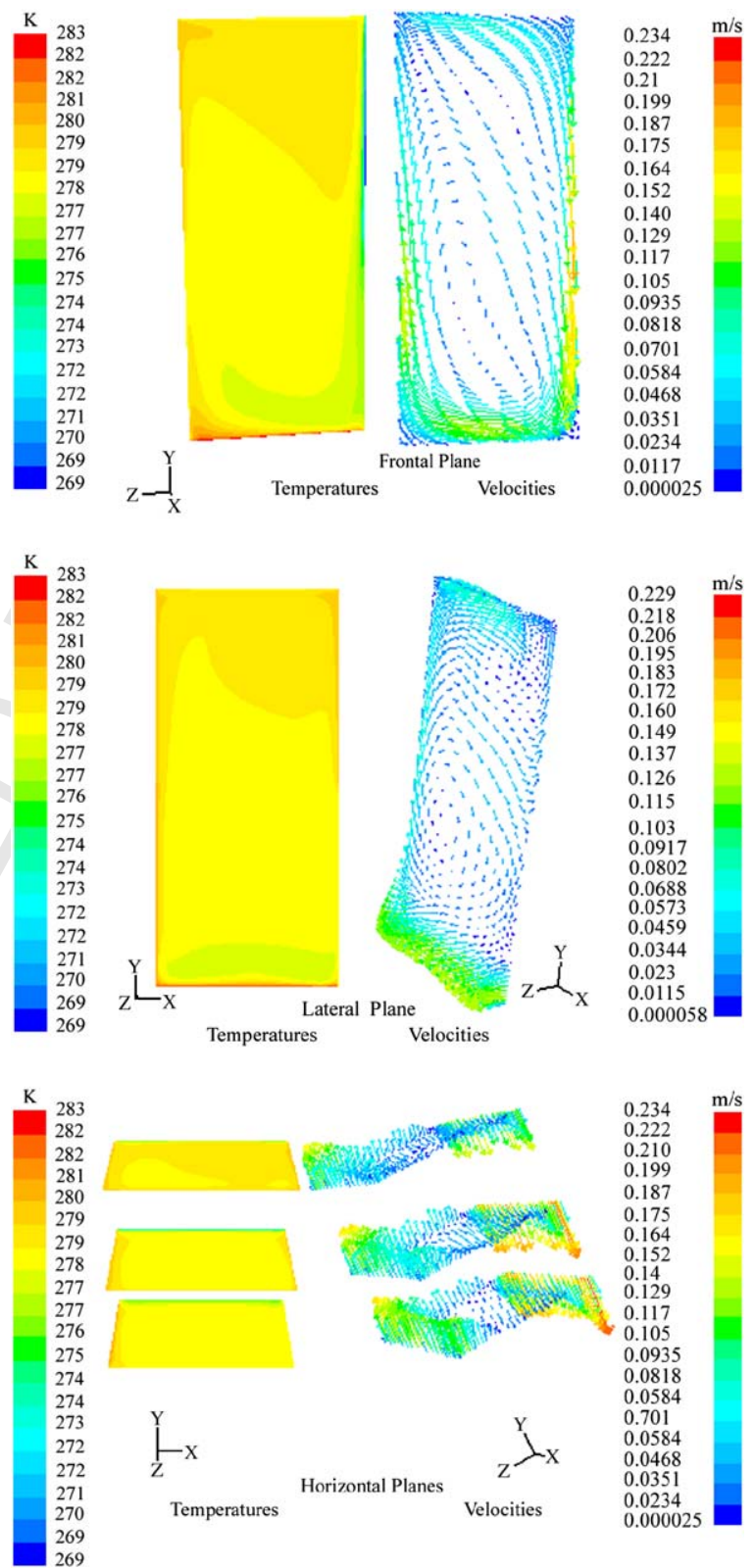

Fig. 5. Results of the thermal simulations with the original refrigerator-freezer.

of the refrigerator where the temperatures are higher than in the bottom of the refrigerator. Thus, changing the placement of the thermostat could contribute to a decrease in the energy consumption of the compressor.

\section{Conclusions}

In this work it was shown that with minor modifications in the available commercial refrigerator-freezers it is 

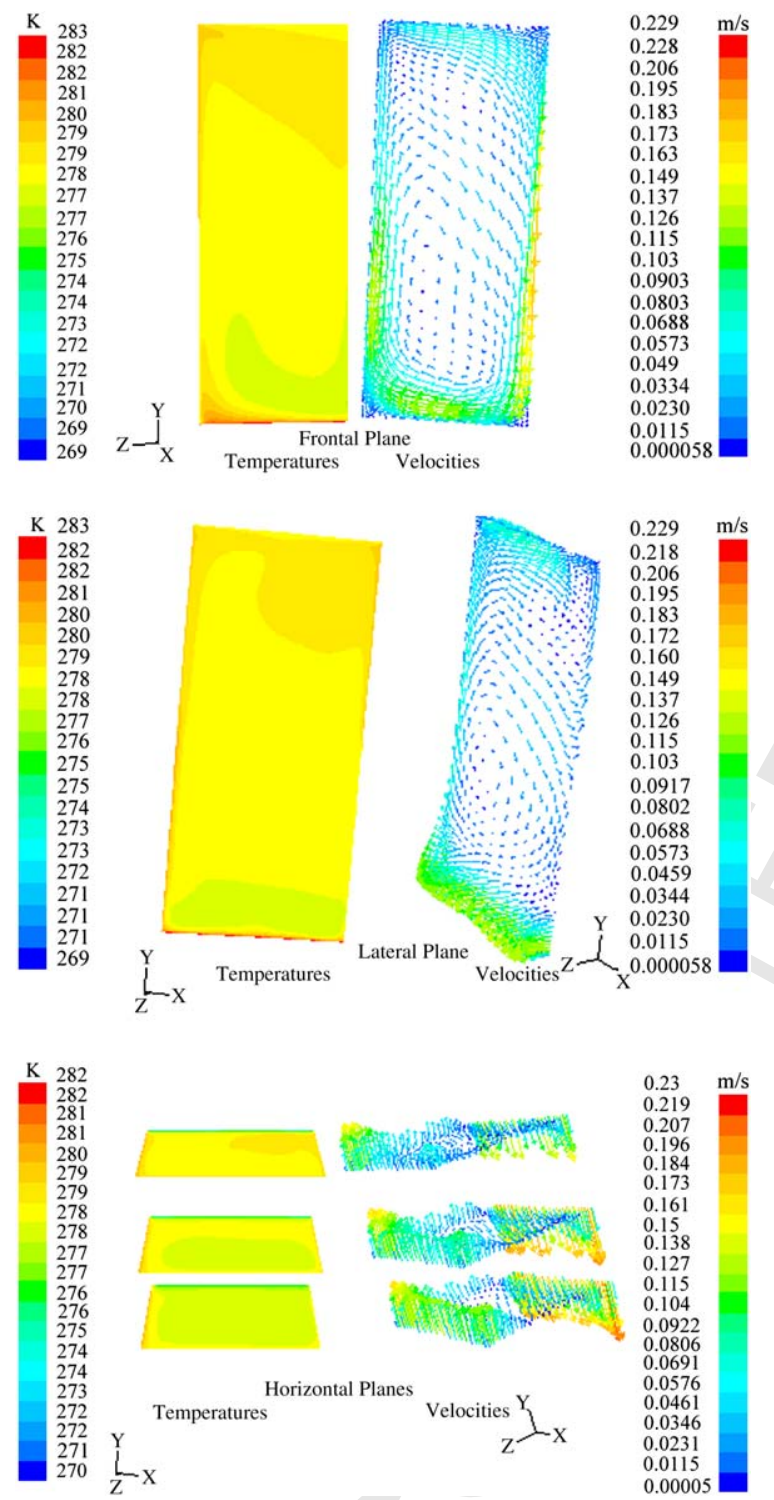

Fig. 6. Results of the thermal simulations with radiation shield in the exterior rear wall and recess compressor.

possible to have a decrease in the inside air temperatures. These modifications simply consist in covering the external rear wall of the refrigerator and the compressor recess wall with a sheet of aluminium foil avoiding in that way the radiation heat transfer from the condenser and the compressor to the external surfaces of the refrigerator.

Results have shown that when those surfaces are covered with a sheet of aluminium foil there is a significant decrease in the inside air temperatures of the refrigerator and of the freezer, about $2 \mathrm{~K}$. This is enough to ensure that the inside air temperatures stay within the limits of the recommended ones. With a proper location of the refrigerator thermostat this can contribute to a lower energy consumption of the compressor.

Thermal simulations of the refrigerator were also done with a commercial code, Fluent, and the results are in full agreement with the temperature measurements carried out (the maximum air temperature difference between the measured and simulated ones was about $1 \mathrm{~K}$ ) which suggests that it is a powerful tool to simulate refrigerators. From the thermal simulations carried out, it is possible to conclude that there are two air flows inside the refrigerator that creates in the middle of the refrigerator, a zone where the air is almost stagnant. Thus perishable products should not be kept in that zone.

\section{Acknowledgements}

The authors are grateful to the support given to this work by Instituto de Engenharia Mecânica, Polo FEUP - IDMEC Porto, Portugal.

\section{References}

[1] R. Saffa, F.A.A. Clito, C.O. Armando, D.A.R. David, Natural refrigerants for refrigeration and air conditioning systems, Applied Thermal Engineering 17 (1997) 33-42.

[2] F.A.A. Clito, C.O. Armando, O Comportamento de Evaporadores e Condensadores de Instalações Frigoríficas Face aos Novos Fluidos Refrigerantes, in: Proceedings of the III Congresso de Engenharia Mecânica do Norte-Nordeste, Brazil, 1994.

[3] W. Gosney, Principles of Refrigeration, Cambridge University Press, Cambridge, 1982.

[4] C.O. Armando, F.A.A. Clito, Services in processing plants: refrigeration, in: Encyclopedia of Dairy Sciences, Academic Press, 2002, pp. 2483-2487.

[5] J. Fearon, Expansion devices, Journal of Refrigeration and Air Conditioning (July 1979) 59-64.

[6] F.A.A. Clito, M. Joaquim, C.O. Armando, Comportamento Térmico de um Frigorífico Doméstico, in: Engenharia e Inovação para o Desenvolvimento, in: Proceedings of the 3rd Congress Luso-Moçambicano in Engineering - CLME' 2003, vol. I, Maputo, Mozambique, 2003. pp. 297-304.

[7] F.A.A. Clito, et al., Frigoríficos Domésticos. Valuation Térmica Frente Varios Regímenes de Funcionamento, in: Proceedings of Advances en Ciencias y Técnicas del Frio, vol. II, Vigo, Spain, 2003. pp. 119-128.

[8] Hewlett Packard, Data Acquisition/Switch Unit, HP 34970A, 1997.

[9] Fluent User's Guide, Version 4.0, Fluent Inc., Lebanon - NH, USA, 1998.

[10] M.G. Kaganer, Thermal Insulation in Cryogenic Engineering, IPST, 1969.

[11] Robert Siegel, J.R. Howell, Thermal Radiation Heat Transfer, Taylor \& Francis Inc., 1992.

[12] International Standard ISO 7371, 1995 (E).

[13] Portuguese Regulamentation, NP 4152, 1991. 
[17] M.L. Hoang, et al., Analysis of the airflow in a cold storage by means of computational fluid dynamics, International Journal of Refrigeration (2000) 127-140.

[18] R. Oliver, H. Michael, Computation of the airflow in a pilot scale clean room using $k-\varepsilon$ turbulence models, International Journal of Refrigeration (2002) 351-361. 